\title{
Zinc chelates as new activators for sulphur vulcanization of acrylonitrile-butadiene elastomer
}

\author{
M. Przybyszewska ${ }^{*}$, M. Zaborski ${ }^{1}$, B. Jakubowski², J. Zawadiak ${ }^{2}$ \\ ${ }^{1}$ Institute of Polymer and Dye Technology, Technical University of Lodz, Stefanowskiego 12/16, Lodz 90-924, Poland \\ ${ }^{2}$ Department of Chemistry, The Silesian University of Technology, Krzywoustego 4, Gliwice 44-100, Poland
}

Received 12 January 2009; accepted in revised form 26 February 2009

\begin{abstract}
The goal of this work was to apply several zinc chelates as activators for sulphur vulcanization of acrylonitrilebutadiene elastomer (NBR), in order to find alternatives for the conventionally used zinc oxide. In this article, we discuss the effects of different zinc complexes on the cure characteristics, crosslinks distribution in the elastomer network and mechanical properties of acrylonitrile-butadiene rubber.

Zinc chelates seem to be good substitutes for zinc oxide as activators for sulphur vulcanization of NBR rubber, without detrimental effects on the crosslinking process and physical properties of the obtained vulcanizates. Moreover, application of zinc complexes allows to reduce the amount of zinc ions in rubber compounds by $40 \%$ compared to conventionally crosslinked vulcanizates with zinc oxide. It is a very important ecological goal since zinc oxide is classified as toxic to aquatic species and its amount in rubber products must be reduced below $2.5 \%$ at least. From a technological point of view it is a very important challenge.
\end{abstract}

Keywords: rubber, nanocomposites, networks, vulcanization, zinc complexes

\section{Introduction}

Zinc is one of the most widespread metals on Earth. It occurs naturally in the environment at moderate levels and is essential for humans to function properly. Its deficiency in the human body has a detrimental effect on growth and immunity. However, there are some aquatic species that seem very sensitive to zinc ions, so some soluble zinc compounds have been classified as toxic to aquatic species.

Since April 2004, the European Union has classified zinc oxide $(\mathrm{ZnO})$ as dangerous for the environment and has legislated that its application in rubber technology be reduced and controlled [1]. From an ecological point of view, $\mathrm{ZnO}$ content must be kept as low as possible.

Zinc oxide is one of the basic components of rubber compounds. It acts as an activator for rubber crosslinking by sulphur or sulphur donors [2, 3], increasing the amount of bound sulphur and the efficiency of the crosslinking system [4]. The mechanism of the crosslinking process in the presence of $\mathrm{ZnO}$ is well known: it reacts with accelerators to form highly active zinc salt [5]. Complexes of $\mathrm{Zn}^{2+}$ ions with accelerators are believed to be more reactive than the free accelerator and allow sulphur insertion to occur more rapidly [6]. Next, the complexes interact with sulphur or sulphur donors, generating the active sulphurating agent, which reacts with allylic sites of rubber chains to form crosslink precursors [7]. Forming these rubber bound intermediates is a key stage in accelerated sulphur vulcanization. The crosslink precursor can react with another polymer chain to generate a crosslink. 
There is discussion about the role of $\mathrm{ZnO}$ in the crosslinking process. According to Nieuwenhuizen [8], the surface of $\mathrm{ZnO}$ acts both as a reactant and a catalytic reaction template, by activating and bringing together reactants. The particles of accelerators, sulphur, and fatty acids diffuse through the polymer matrix and are adsorbed on the surface of zinc oxide, forming intermediate complexes. From this point of view, the dispersion of $\mathrm{ZnO}$ in the elastomer matrix is the most important parameter. Mark et al. [9] proved that adding zinc oxide affects different stages of the vulcanization process. It increases the rate of formation of the crosslink precursors, but also decreases the rate of final crosslink formation. Chapman and Porter [10] investigated the role of the zinc activator in accelerated vulcanization of natural rubber (NR). According to their studies, zinc oxide has little effect on the vulcanization rate, but increases the crosslinking efficiency. Moreover, when zinc oxide is present, sulphuration is mainly caused by substituting allylic hydrogen atoms, rather than by combining substitution and addition to the $\mathrm{C}=\mathrm{C}$ double bonds. In this way, crosslink shortening is catalyzed, a network with a greater proportion of mono- and disulphidic crosslinks is formed, and the reversion is reduced. The presence of zinc oxide also leads to a small increase in scorch safety and cure time [1]. Zinc oxide can also be used as a crosslinking agent, e.g., of carboxylic rubbers $[5,11]$ and elastomers containing halogen groups [12]. Moreover, $\mathrm{ZnO}$ is sometimes applied as filler in elastomers, although some technological problems are encountered during preparation of mixtures (weak dispersion) [13]. There is also evidence that zinc oxide has a significant influence on physical properties of vulcanizates, such as heat build-up and abrasion resistance.

Since zinc cations from zinc oxide react with accelerators and cause active zinc-accelerator complexes (the key step in the vulcanization process), in order to increase the activity of zinc oxide, the availability of zinc ions should be increased. Due to the crystalline structure of $\mathrm{ZnO}$, some ions are inside crystals and have limited accessibility. In order to reduce the amount of zinc compounds in rubber technology, it is necessary to incorporate more chemically active zinc into the elastomer matrix, in the form of reactive complexes.
In this work, we applied zinc chelates with 1,3diketones as activators for crosslinking of acrylonitrile-butadiene rubber (NBR). It is believed that zinc chelates can be dispersed more easily in the elastomer matrix and that the accessibility of zinc ions is higher, although applications of such activators have not yet been reported.

\section{Experimental section}

\subsection{Materials}

Acrylonitrile-butadiene rubber NBR (Nipol DN 4050) containing $40 \mathrm{wt} \%$ of acrylonitrile was obtained from Zeon-Europe $\mathrm{GmbH}$. Its Mooney viscosity was (ML1+4 $\left(100^{\circ} \mathrm{C}\right)$ : 46-60). It was cured with sulphur in the presence of 2-mercaptobenzothiazole (MBT). Nanosized zinc oxide with specific surface area $42.5 \mathrm{~m}^{2} / \mathrm{g}$ and average particle size $234 \mathrm{~nm}$ (Qinetiq Nanomaterials Limited, Hampshire) together with stearic acid (SigmaAldrich) was applied as standard activator. As new activators of sulphur vulcanization, zinc chelates with 1,3-diketones as well as zinc acetylacetonate (Riedel-de Haën) were used. Zinc chelates with 1,3-diketones were synthesized using commercially available diketones according to the following procedure. Diketone was dissolved in acetone, then the water solution of potassium hydroxide was added to form potassium salt of diketone. The mixture was heated until it started to boil and water solution of zinc chloride was added. Afterwards, the mixture was heated for $1 \mathrm{~h}$ forming a precipitate of zinc chelate. The structures of the zinc complexes are given in Figure 1.

\subsection{Preparation and characterization of rubber compounds}

Rubber compounds with the formulations given in Table 1 were prepared using a laboratory two-roll mill. The samples were cured at $160^{\circ} \mathrm{C}$ until they developed a $90 \%$ increase of torque (measured using oscillating disc rheometer produced by ZACH METALCHEM). The tensile properties of vulcanizates were determined according to ISO-37 with a universal machine ZWICK 1435. The crosslinking density of vulcanizates was determined by equilibrium swelling in toluene, based on the Flory-Rehner equation [14] using Huggins 


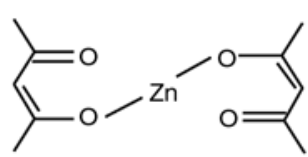

a)

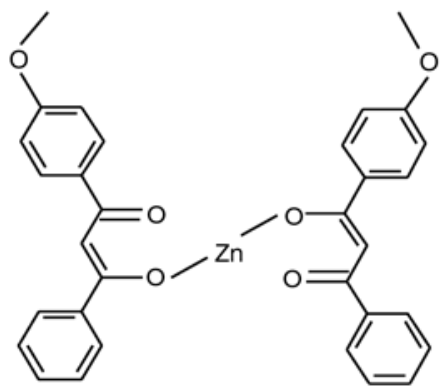

d)

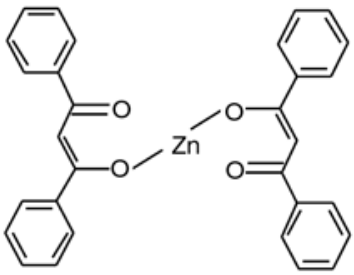

b)

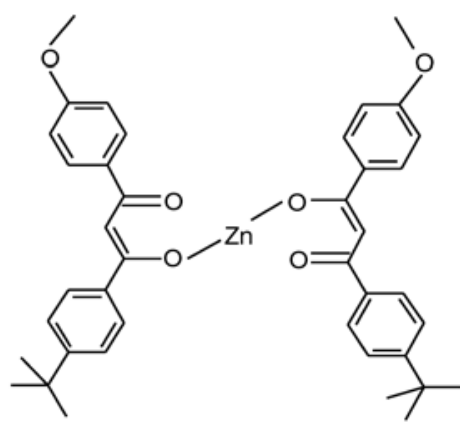

c)

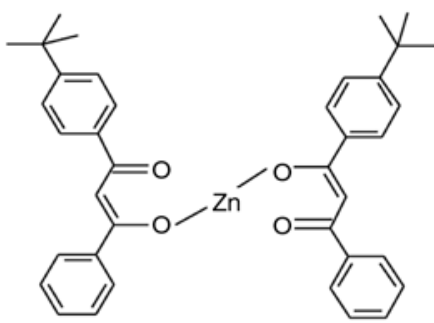

f)

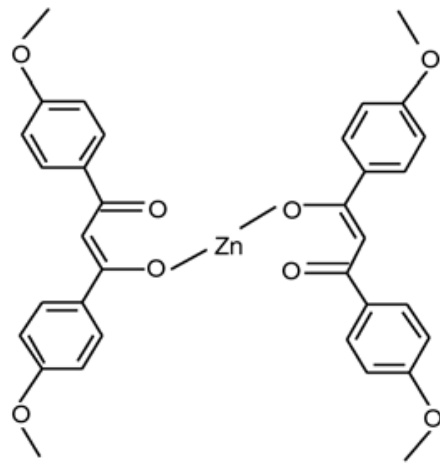

Figure 1. Zinc containing activators: a) zinc acetylacetonate AAC-Zn, b) zinc 1,3-diphenylpropane-1,3-dione BM-Zn, c) zinc 1-(4'-t-butylphenyl)-3-phenylpropane-1,3-dione BBM-Zn, d) zinc 1-(4'-methoxyphenyl)-3-phenylpropane-1,3-dione MBM-Zn, e) zinc 1-(4'-t-butylphenyl)-3-(4"-methoxyphenyl)propane-1,3-dione MBBM, f) zinc 1,3-bis-(4'methoxyphenyl)propane-1,3-dione MMBM-Zn

Table 1. Composition of the NBR based rubber compounds [phr]

\begin{tabular}{|l|c|c|c|c|c|c|c|}
\hline \multicolumn{1}{|c|}{ Compound } & M1 & M2 & M3 & M4 & M5 & M6 & M7 \\
\hline NBR & 100 & 100 & 100 & 100 & 100 & 100 & 100 \\
\hline Sulphur & 2 & 2 & 2 & 2 & 2 & 2 & 2 \\
\hline Accelerator (MBT) & 2 & 2 & 2 & 2 & 2 & 2 & 2 \\
\hline Nano ZnO & 2 & - & - & - & - & - & - \\
\hline Stearic acid & 2 & - & - & - & - & - & - \\
\hline Zinc chelates & - & $3^{\mathrm{a}}$ & $3^{\mathrm{b}}$ & $3^{\mathrm{c}}$ & $3^{\mathrm{d}}$ & $3^{\mathrm{e}}$ & $2^{\mathrm{f}}$ \\
\hline
\end{tabular}

where a - BM-Zn, b - BBM-Zn, c - MBM-Zn, d - MBBM-Zn, e - MMBM-Zn, f - AAC-Zn

parameter of elastomer-solvent interaction $\mu=$ $0.381+0.671 V_{r}($ Equation (1)):

$v_{e}=-\frac{\ln \left(1-V_{r}\right)+V_{r}+\mu V_{r}^{2}}{V_{0}\left(V_{r}^{\frac{1}{3}}-\frac{V_{r}}{2}\right)}$

where $v_{e}$ crosslinking density, $V_{r}$ volume fraction of elastomer in swollen gel, $V_{0}$ molar volume of solvent $\left[\mathrm{mol} / \mathrm{cm}^{3}\right]$.

\subsection{Surface properties of zinc chelates}

The surface properties of zinc chelates were determined based on zeta potential measurements using a Zetasizer 2000 apparatus. The zeta potentials of zinc complex suspensions in water were measured as a function of $\mathrm{pH}$. The concentration of suspen- sions was $0.02 \mathrm{~g} / \mathrm{l}$, and the $\mathrm{pH}$ was adjusted by adding $\mathrm{HCl}$ or $\mathrm{NaOH}$ solution.

\subsection{Stability of zinc complexes}

Stability of the examined zinc complexes was estimated based on the heat of zinc complex formation, which was calculated using HyperChem Release 7 software. It allowed to explore the structure and stability of zinc complex molecules using quantum mechanics. The HyperChem was used to create the starting geometries and refine molecular configurations of zinc complex structure. The molecules were constructed and converted to 3D structures. Next, the torsion angles between molecules fragments were varied and a full optimization of the structure geometry was performed to find the most stable one, which exhibits the lowest energy. After geometry optimization, the semi-empirical method 
AM1 was applied to calculate the heat of formation of the possible zinc complex molecular structures.

\subsection{Heterogeneity of elastomer network}

The distribution of crosslinks in the elastomer network was estimated based on solvent freezing point depression of solvent confined in the polymer gel. Thermograms of solidification were recorded on a Differential Scanning Calorimetry (DSC) instrument (Perkin-Elmer DSC 7) by decreasing the temperature from 30 to $-90^{\circ} \mathrm{C}$ at a rate of $10^{\circ} \mathrm{C} / \mathrm{min}$. Prior to this measurement, samples were swollen in benzene for 24 hours [15].

\subsection{Dispersion of zinc chelates in elastomer matrix}

The distribution of activator particles (zinc oxide and zinc complexes) was estimated using Scanning Electron Microscopy with a SEM microscope LEO 1530.

\section{Results and discussion}

\subsection{Surface properties of zinc complexes}

The zeta potential is an electrokinetic potential measured on the surface of a particle in solution. A charged surface results in the formation of an electric double layer, and the zeta potential is the potential between the charged surface and the electrolyte solution [16]. We examined the zeta potential of water-zinc chelates suspensions versus $\mathrm{pH}$ (Figure 2).

From the zeta potential measurements, we determined the isoelectric point (IEP) of zinc chelates. IEP is the $\mathrm{pH}$ value at which the zeta potential is equal zero. It is not a description of the absolute basicity or acidity of solid surface, but a description of their relative strength. A high IEP value indi-

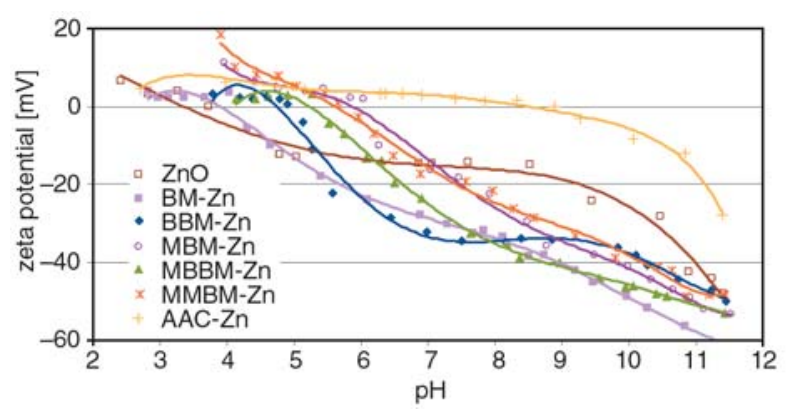

Figure 2. Zeta potential of zinc chelates
Table 2. Isoelectric points of zinc complexes

\begin{tabular}{|l|c|}
\hline \multicolumn{1}{|c|}{ Zinc complex } & Isoelectric point (IEP) \\
\hline Nano ZnO & 3.7 \\
\hline BM-Zn & 4.2 \\
\hline BBM-Zn & 4.9 \\
\hline MBM-Zn & 5.8 \\
\hline MBBM-Zn & 5.3 \\
\hline MMBM-Zn & 5.7 \\
\hline AAC-Zn & 8.7 \\
\hline
\end{tabular}

cates that the surface shows more basic functionality compared with its acidic functionality. On the contrary, a low IEP surface reveals less basic functionality comparing with its acidic functionality [13]. IEP is mainly related to the Brönsted acidbase definition. The higher IEP corresponds to stronger affinity to protons. However, IEP is also a measure of Lewis acidity or basicity, because when the oxide surface adsorbs a proton, the electron (or electron density) is transferred from oxygen to proton. Therefore, a strong proton acceptor is also a strong electron donor [16].

The isoelectric point (IEP) of zinc oxide was determined at $\mathrm{pH} 3.8$, whereas the IEP for zinc chelates was determined within the $\mathrm{pH}$ range from 4.2 (for $\mathrm{BM}-\mathrm{Zn}$ ) to 5.8 (for MBM-Zn) and at $\mathrm{pH} 8.7$ for zinc acetylacetonate AAC-Zn. This indicates acid properties of zinc complex surfaces (especially $\mathrm{BM}-\mathrm{Zn}$ and $\mathrm{BBM}-\mathrm{Zn}$ ), similar to pure $\mathrm{ZnO}$ (the

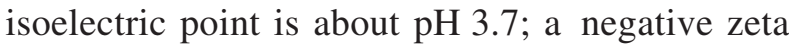
potential was determined in almost the whole range of measured $\mathrm{pH}$ ) and basic properties of zinc acetylacetonate (a positive zeta potential and IEP at $\mathrm{pH}$ 8.7). Results are given in Table 2.

It should be noticed that zinc complexes with the most similar to zinc oxide surface properties exhibited the highest activity in crosslinking process. This could be due to their similar ability to interact with other components of crosslinking system (accelerator, sulphur) or with elastomer matrix.

\subsection{Stability of zinc complexes}

The stability of zinc complexes is considered to determine the effectiveness of zinc ions and the tendency of complexes to form intermediate active sulphurating agents during vulcanization. We therefore calculated the heat of zinc complex formation. It is known that the higher the heat of formation, the lower the stability of the compound. We also estimated the stability of a zinc complex with accel- 
Table 3. Heat of zinc complex formation

\begin{tabular}{|l|c|}
\hline \multicolumn{1}{|c|}{ Zinc complex } & Heat of formation [kJ/mol] \\
\hline BM-Zn & 206.5 \\
\hline BBM-Zn & 140.9 \\
\hline MBM-Zn & -114.8 \\
\hline MBBM-Zn & -271.7 \\
\hline MMBM-Zn & -437.0 \\
\hline AAC-Zn & -395.1 \\
\hline Zn-MBT & 544.5 \\
\hline
\end{tabular}

erator (2-mercaptobenzothiazole), which is formed during vulcanization when zinc oxide is present in the rubber compound (see results in Table 3 ).

In the more stable chelates, zinc ions have a reduced availability and lower tendency to form the zinc-accelerator complex during vulcanization process. Therefore, due to the lowest stability of 1,3-diphenylpropane-1,3-dione and 1-(4'-t-butylphenyl)-3-phenylpropane-1,3-dione (BM-Zn and $\mathrm{BBM}-\mathrm{Zn}$ respectively), these were expected to influence the crosslinking process the most.

Zinc complexes exhibit lower heat of formation and higher stability than Zn-MBT complex, which is formed when zinc oxide is used as activator. Therefore, this system should be more accelerated than BM-Zn or BBM-Zn. However, the reduced availability of zinc ions in $\mathrm{ZnO}$ crystals comparing to zinc chelates causes the decrease in the rate of formation of zinc-accelerator complex during vulcanization process. As a result the cure rate of rubber compounds containing zinc oxide is smaller than BM-Zn or BBM-Zn chelates.

\subsection{Effect of zinc complexes on vulcanization}

The influence of zinc chelates on the cure characteristics of rubber compounds was estimated based on rheometer measurements. The cure characteris-

Table 4. Cure characteristics of NBR compounds

\begin{tabular}{|l|c|c|c|c|}
\hline \multicolumn{1}{|c|}{ Compound } & $\begin{array}{c}\Delta \mathbf{G} \\
{[\mathbf{d N m}]}\end{array}$ & $\begin{array}{c}\mathbf{t}_{\mathbf{9 0}} \\
{[\mathbf{m i n}]}\end{array}$ & $\mathbf{n}$ & $\begin{array}{c}\mathbf{k}^{\mathbf{1}} \\
{\left[\mathbf{s}^{-\mathbf{1}} \mathbf{3}\right.}\end{array}$ \\
\hline NBR/nano ZnO & 68.0 & 70 & 2 & 7.0 \\
\hline NBR/BM-Zn & 24.9 & 25 & 2 & 76.2 \\
\hline NBR/BBM-Zn & 24.0 & 20 & 2 & 84.0 \\
\hline NBR/MBM-Zn & 40.8 & 60 & 2 & 13.3 \\
\hline NBR/MBBM-Zn & 63.2 & 75 & 2 & 5.4 \\
\hline NBR/MMBM-Zn & 54.6 & 50 & 2 & 20.3 \\
\hline NBR/AAC-Zn & 38.8 & 50 & 2 & 18.5 \\
\hline
\end{tabular}

$\Delta G$ - increment of torque in the rubber compound during vulcanization; $t_{90}$ - optimal vulcanization time; $n$ - order of the crosslinking reaction; $k$ - the constant of the vulcanization rate

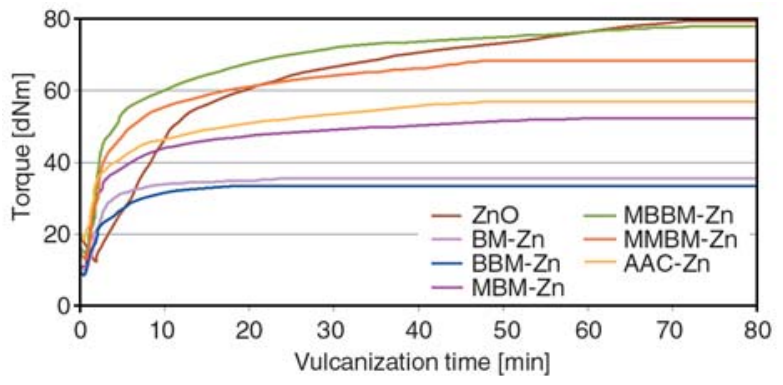

Figure 3. Rheometer isotherms of NBR compounds containing zinc complexes

tics of NBR compounds with different activators are given in Table 4 and Figure 3.

Applying zinc chelates resulted in a higher cure rate compared to the conventional $\mathrm{ZnO}$ system, despite the fact that the zinc ion content in the cure system is several times smaller (Table 5). We believe that the increase in cure rate may be due to better availability of zinc ions in zinc complexes than in zinc oxide crystals. The zinc ions trapped in a crystal of $\mathrm{ZnO}$ are not used for crosslinking due to their limited accessibility. From this point of view, the crystal structure of $\mathrm{ZnO}$ is the most important parameter. The most common crystal structure of $\mathrm{ZnO}$ is wurtzite (zincite) [17], which has a hexagonal geometry, with each zinc atom surrounded by a tetrahedron of oxygen atoms. The whole structure consists of an interconnected network of tetrahedra. Based on $\mathrm{ZnO}$ lattice parameters [18], the amount of zinc ions available in a single crystal is estimated to be $1.8 \mathrm{mmole} / \mathrm{g}$ of $\mathrm{ZnO}$. Therefore, the calculated amount of $\mathrm{Zn}^{2+}$ available for interaction with sulphur and accelerators in examined rubber compound is $3.6 \mathrm{mmole} \mathrm{Zn}^{2+} / 100 \mathrm{~g}$ of elastomer. Moreover, $\mathrm{Zn}^{2+}$ ions in the $\mathrm{ZnO}$ nanoparticle are strongly connected to the crystal structure, and are less likely to form intermediate active sulphurating agents that can be observed during vulcanization.

Table 5. Zinc content in zinc complexes applied in rubber compounds

\begin{tabular}{|l|c|c|}
\hline \multicolumn{1}{|c|}{ Activator } & $\begin{array}{c}\mathbf{Z n}^{\mathbf{2 +}} \\
\text { in activator } \\
{[\mathbf{m m o l e} / \mathbf{g}]}\end{array}$ & $\begin{array}{c}\mathbf{Z n}^{\mathbf{2 +}} \text { content in } \\
\text { rubber compound } \\
\text { [mmole/100 g NBR] }\end{array}$ \\
\hline $\mathrm{ZnO}$ (in bulk) & 12.3 & 24.6 \\
\hline $\mathrm{ZnO}$ (on crystal surface) & 1.8 & 3.6 \\
\hline BM-Zn & 2.0 & 6.0 \\
\hline BBM-Zn & 1.6 & 4.8 \\
\hline MBM-Zn & 1.7 & 5.2 \\
\hline MBBM-Zn & 1.5 & 4.5 \\
\hline MMBM-Zn & 1.6 & 4.8 \\
\hline AAC-Zn & 3.8 & 7.6 \\
\hline
\end{tabular}


For vulcanization rate, the most effective activators seemed to be BM-Zn and BBM-Zn (Table 4). For rubber compounds containing these activators the shortest times of vulcanization and simultaneously the highest constants of vulcanization rate were determined. The lower efficiencies of AAC-Zn, MBM-Zn, MBBM-Zn and MMBM-Zn are probably related to the high stability of these complexes. In the cases of MBBM-Zn and MMBM-Zn, the steric hindrance of methoxy groups and t-butyl chains in a complex molecule (see Figure 1), which reduces the availability of zinc ions to form the zinc-accelerator complex, may also cause the lower efficiency of these complexes in vulcanization. According to Heideman et al. [7] different reactivities of zinc complexes result from their different basicity. The alkaline character of activator accelerates the sulphur vulcanization of rubber. Methoxy and t-butyl groups are known for their electronwithdrawing and electron donating abilities, which could affect the strength of the coordination bonds in the zinc complexes and therefore, the degree of their ionic nature. However, considering the structure of all zinc chelates with 1,3-diketones as well as the results of zeta potential measurements, which confirmed quite similar acid-base properties of zinc chelates, we concluded, that the main reasons of their different reactivity in crosslinking process are differences in complexes stability and availability of zinc ions in zinc complex molecule.

The considerably lower torque that was observed for compounds with zinc chelates had no detrimental effect on the physical properties of obtained vulcanizates.

\subsection{Crosslink density of vulcanizates and the distribution of crosslinks in elastomer network}

We analyzed the influence of different zinc activators on the crosslink density of NBR vulcanizates. The crosslink density was determined by equilibrium swelling of vulcanizates in toluene. Results are given in Table 6 .

From the data presented, it follows that applying zinc complexes as activators in sulphur vulcanization of NBR had a detrimental effect on the crosslink density. The calculated values of crosslink density confirmed that the most effective zinc complexes in vulcanization were BM-Zn and BBM-Zn.
Table 6. Crosslink density of NBR vulcanizates containing zinc complexes

\begin{tabular}{|l|c|c|c|}
\hline \multicolumn{1}{|c|}{ Vulcanizate } & $\mathbf{Q}_{\mathbf{w}}$ & $\begin{array}{c}\mathbf{v}_{\mathbf{e}} \cdot \mathbf{1 0}^{\mathbf{3}} \\
{\left[\mathbf{m o l e}_{\mathbf{c}} \mathbf{c m}^{\mathbf{3}} \text { ] }\right.}\end{array}$ & $\begin{array}{c}\mathbf{E} \text { [crosslinks/mole } \\
\text { of sulphur] }\end{array}$ \\
\hline NBR/nano ZnO & 1.34 & 11.7 & 1.50 \\
\hline NBR/BM-Zn & 1.42 & 11.0 & 1.41 \\
\hline NBR/BBM-Zn & 1.39 & 11.3 & 1.45 \\
\hline NBR/MBM-Zn & 1.64 & 9.4 & 1.21 \\
\hline NBR/MBBM-Zn & 1.62 & 9.6 & 1.23 \\
\hline NBR/MMBM-Zn & 1.63 & 9.5 & 1.22 \\
\hline NBR/AAC-Zn & 1.51 & 10.3 & 1.32 \\
\hline
\end{tabular}

$Q_{w}$ - equilibrium swelling of vulcanizate in toluene;

$v_{e}-$ crosslink density of vulcanizate; $E$ - crosslinking efficiency

This seems even more important when we realize that the content of $\mathrm{Zn}^{2+}$ ions in $1 \mathrm{phr}$ of $\mathrm{BM}-\mathrm{Zn}$ and $\mathrm{BBM}-\mathrm{Zn}$ is about six times smaller than in $1 \mathrm{phr}$ of applied nanosized zinc oxide. A considerable decrease in crosslink density compared to conventional $\mathrm{ZnO}$ was observed when MBM-Zn, MBBM$\mathrm{Zn}$ and MMBM-Zn were used as activators. The highest activity of BM-Zn and BBM-Zn chelates in vulcanization was also confirmed by the calculated values of crosslinking efficiency (Table 6). Only $\mathrm{BM}-\mathrm{Zn}$ and BBM-Zn chelates allowed to achieve the crosslinking efficiency comparable with nanosized zinc oxide.

Apart from crosslink density, the distribution of crosslinks and the presence of defects in the elastomer network have a great importance as far as the mechanical properties of vulcanizates are concerned [19]. In other words, not only the number of crosslinks, but also their distribution and spatial arrangements contribute to the network mechanical performance. From a mechanical point of view, the heterogeneous distribution of crosslinks in the elastomer network is supposed to have a detrimental effect on mechanical properties of vulcanizates if we assume that densely crosslinked domains of the network concentrate stresses under external strain and initiate breaking of the sample. Therefore, vulcanizates with homogeneous structure exhibit higher tensile strength [20]. Vilgis and Henrich [21] postulated that heterogeneity of the network strongly affects the vulcanizate behavior under high strain and therefore, such mechanical properties as tensile strength and elongation at break. In less crosslinked part of the network the distribution of stress in crosslinked sample can be more effective as a result of stress relaxation. The propagation of microcracks within these areas could be hin- 
dered and microcracks could rise only under higher stresses and deformations. As a result materials tensile strength and elongation at break increase.

The crosslink distributions in an NBR matrix were estimated based on freezing point depression of solvents confined in a polymer gel. It is a simple method to determine network structure in rubber composites. The freezing point depends on the conditions required for the formation of crystalline nuclei, that is limited by elastomer network restrictions and limitations in movement of polymer chains. From the data presented in Figures 4-8, it follows that the freezing point depression of solvent in swollen elastomer network depends on the crosslink structure. Two peaks were observed on DSC curves. The first, detected at $\left(-6^{\circ} \mathrm{C}\right)$, is due to the crystallization of free benzene. The other corresponds to the crystallization of benzene entrapped in the swollen gel; its position depends on the crosslink density. The peak of confined solvent is shifted towards a lower temperature compared to the free benzene peak. In the case of vulcanizates crosslinked in the presence of zinc complexes (Figures 4-8), the peak of benzene entrapped in the

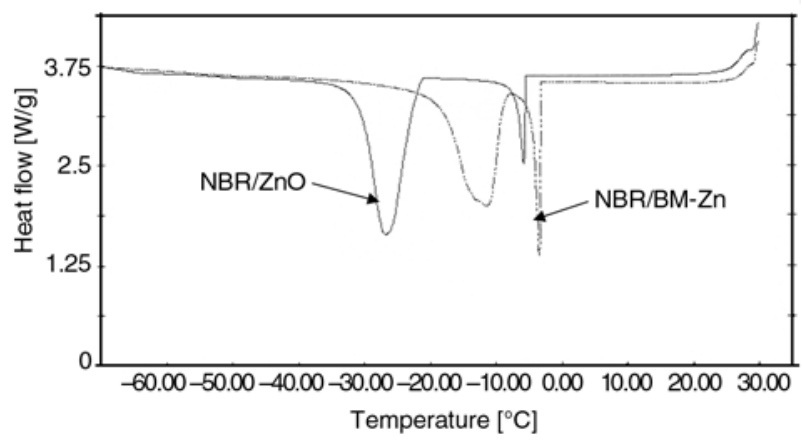

Figure 4. DSC thermogram of swollen NBR vulcanizates containing: zinc oxide (continuous line), BM-Zn chelate (broken line)

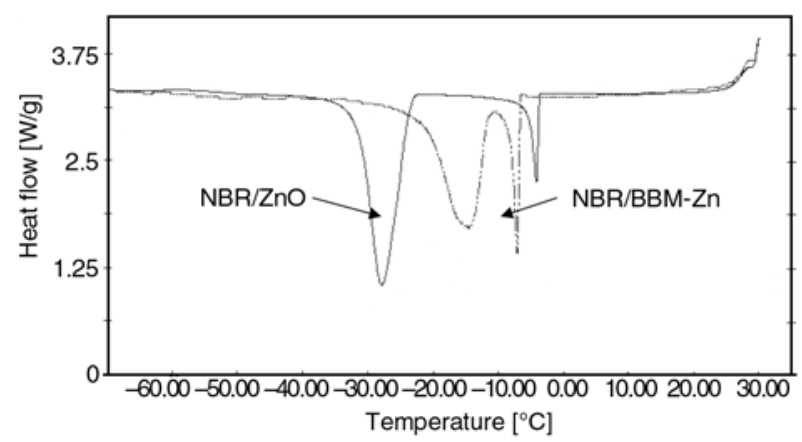

Figure 5. DSC thermogram of swollen NBR vulcanizates containing: zinc oxide (continuous line), BBM$\mathrm{Zn}$ chelate (broken line) swollen network is shifted towards higher temperatures compared to a vulcanizate containing conventional zinc oxide. This behavior corresponds to a decrease of network density, which agrees with the spatial structure parameters of vulcanizates given in Table 6. Moreover, broadening of solidification peaks suggests broadening of the distribution of mesh sizes.

According to Baba [15], the peak position of the solvent confined in the polymer gel is directly related to the radius of the mesh $\left(R_{p}\right)$ by the Equation (2):

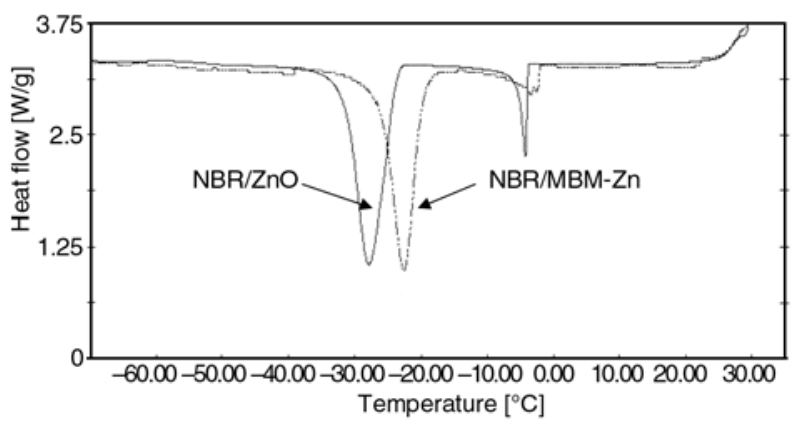

Figure 6. DSC thermogram of swollen NBR vulcanizates containing: zinc oxide (continuous line), MBM-Zn chelate (broken line)

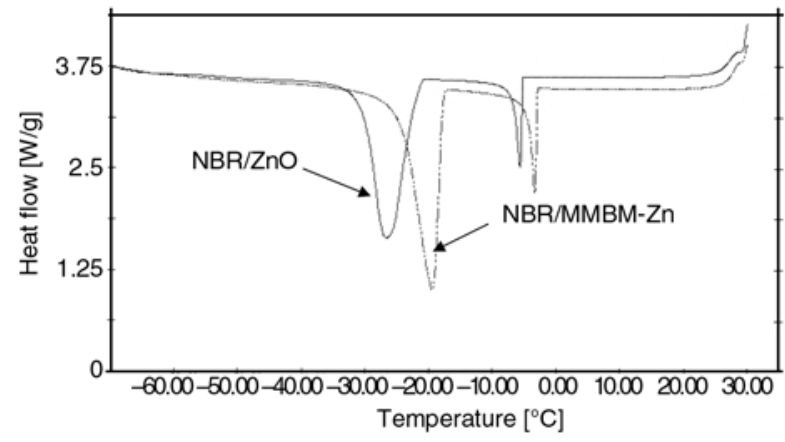

Figure 7. DSC thermogram of swollen NBR vulcanizates containing: zinc oxide (continuous line), MMBM-Zn chelate (broken line)

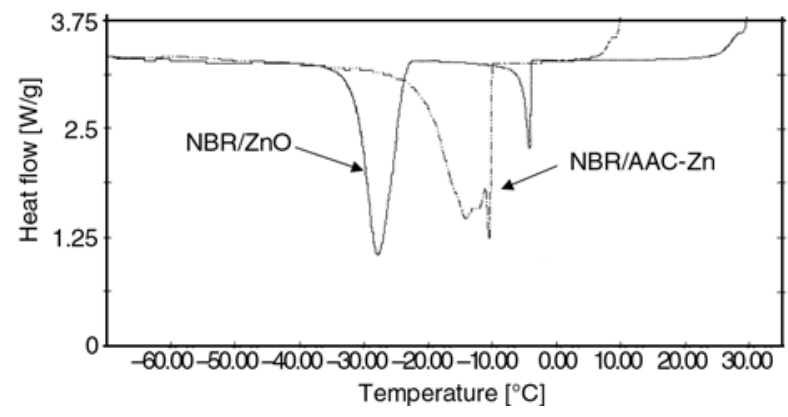

Figure 8. DSC thermogram of swollen NBR vulcanizates containing: zinc oxide (continuous line), AAC-Zn complex (broken line) 


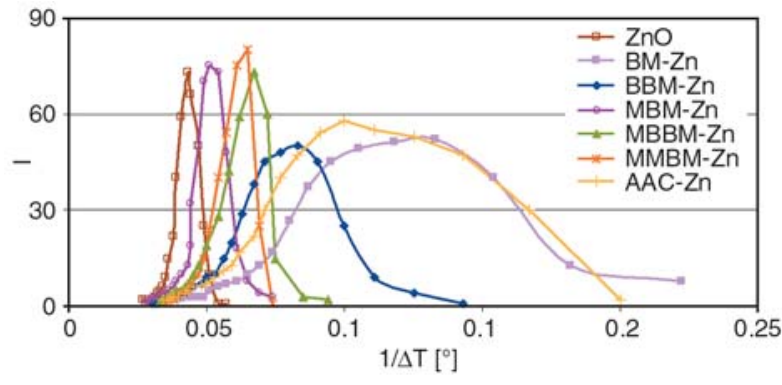

Figure 9. Distribution of molecular weights (I) between network crosslinks in vulcanizates containing zinc complexes

$R_{p}=\frac{-A}{\Delta T}+B$

where $\Delta T=T_{0}-T ; T_{0}$ is the triple point temperature of solvent; and $A, B$ are constants depending on the solvent.

The radius of the mesh is proportional to the molecular weight of the network between crosslinks $M_{c}$. Therefore, to analyze the vulcanizate structures, we estimated the distribution of molecular weights between crosslinks. Results are presented in Figure 9.

Parameter $I$ corresponds to the molecular weight of the network between crosslinks and was estimated based on the peak intensity of benzene confined in a swollen gel. The data presented in Figure 9 indicates that the distribution of crosslinks in the elastomer network resembles a Gaussian distribution. However, broadening of the crosslink distribution was observed for vulcanizates obtained with AAC$\mathrm{Zn}, \mathrm{BM}-\mathrm{Zn}$ and MBBM-Zn zinc complexes. Therefore, it can be concluded that the elastomer networks obtained using these zinc chelates are more heterogeneous than those formed with zinc oxide as the activator. On the contrary the crosslinks distribution in vulcanizates with MBM-Zn and MMBM$\mathrm{Zn}$ complexes was narrower. Vulcanizates with

Table 7. Mechanical properties of NBR vulcanizates containing zinc complexes

\begin{tabular}{|l|c|c|c|}
\hline \multicolumn{1}{|c|}{ Vulcanizate } & $\begin{array}{c}\mathbf{S E}_{\mathbf{3 0 0}} \\
{[\mathbf{M P a}]}\end{array}$ & $\begin{array}{c}\text { TS } \\
{[\mathbf{M P a}]}\end{array}$ & $\begin{array}{c}\text { EB } \\
{[\%]}\end{array}$ \\
\hline NBR/nano ZnO & 2.7 & 10.3 & 541 \\
\hline NBR/BM-Zn & 2.1 & 16.8 & 621 \\
\hline NBR/BBM-Zn & 2.3 & 15.6 & 609 \\
\hline NBR/MBM-Zn & 1.7 & 9.2 & 724 \\
\hline NBR/MBBM-Zn & 1.3 & 13.8 & 766 \\
\hline NBR/MMBM-Zn & 1.5 & 12.7 & 721 \\
\hline NBR/AAC-Zn & 2.6 & 15.0 & 706 \\
\hline
\end{tabular}

SE300 - stress at $300 \%$ relative elongation; TS - tensile strength; $\mathrm{EB}$ - elongation at break heterogeneous networks exhibited considerably higher tensile strength (see results in Table 7). Therefore, the heterogeneity of the network helps improve the vulcanizate mechanical properties.

\subsection{Mechanical properties of vulcanizates}

Having established the effect of zinc chelates on the vulcanization of rubber compounds, we then examined the mechanical properties of vulcanizates. Results are given in Table 7.

From the data compiled in Table 7, it follows that applying zinc chelates considerably increased the tensile strength of vulcanizates compared to using conventional $\mathrm{ZnO}$. The stress at a relative elongation of $300 \%$ slightly decreased, which may be a result of the crosslink density decrease. It is worth noticing that vulcanizates containing zinc complexes have a higher elongation at break corresponding to their higher elasticity.

As far as the tensile strength of vulcanizates is concerned, the most effective appeared to be zinc acetylacetonate, BM-Zn and BBM-Zn complexes, much like the cure characteristics presented in the previous section. These zinc complexes contain higher $\mathrm{Zn}^{2+}$ ion content and have the best availability of these ions as well. However, using MMBM$\mathrm{Zn}$ and MBM-Zn especially had a detrimental effect on the tensile strength of vulcanizates. The explanation for the deterioration of mechanical properties may be: difficult availability of zinc ions in chelates due to steric hindrance, lower content of $\mathrm{Zn}^{2+}$ ions compared to other complexes, the presence of methoxy groups in the complex molecule as well as homogeneity of elastomer network (according to DSC thermograms in Figures 6 and 7). It should be noticed that vulcanizate containing MBBM-Zn exhibited high tensile strength and elongation at break despite lower zinc ions content and the presence of methoxy groups. It could be a result of network heterogeneity. This observation confirmed that elastomer network heterogeneity caused the improvement of vulcanizates physical properties.

\subsection{Dispersion of zinc chelates in elastomer matrix}

Assuming that the particles of accelerators, sulphur, and fatty acids diffuse through the polymer 
matrix and are adsorbed on the surface of zinc oxide forming intermediate complexes [6], the dispersion of zinc oxide particles in the elastomer matrix has a great importance as far as the activation of sulphur vulcanization is concerned. SEM images of the vulcanizate surfaces were taken to estimate the dispersion of activator particles in the elastomer (Figures 10a-10f).

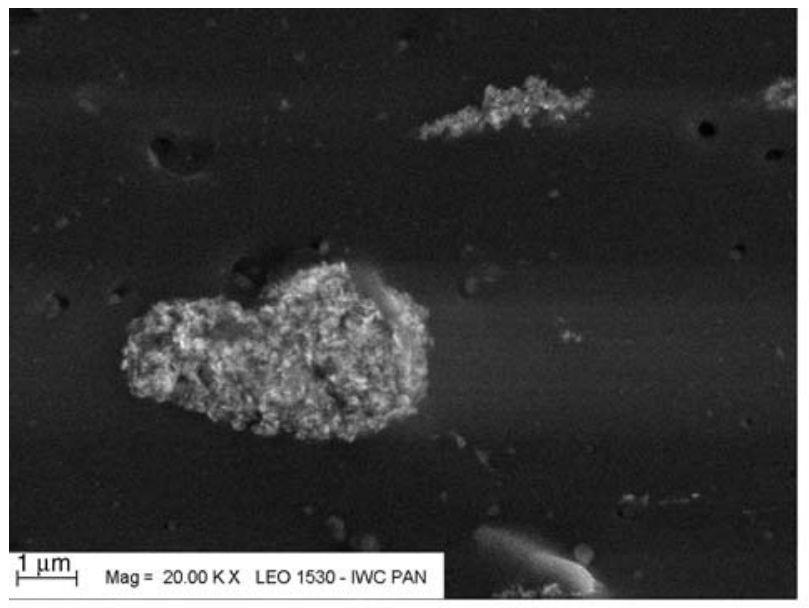

a)

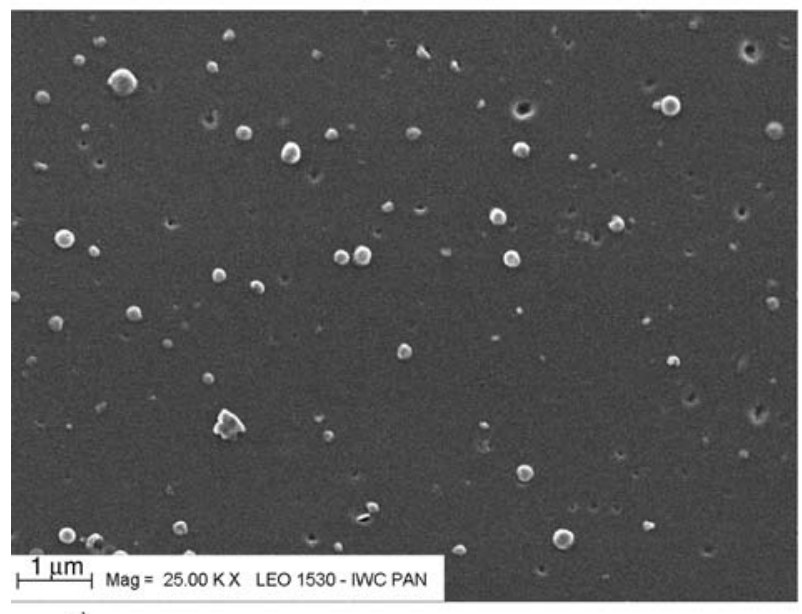

c)

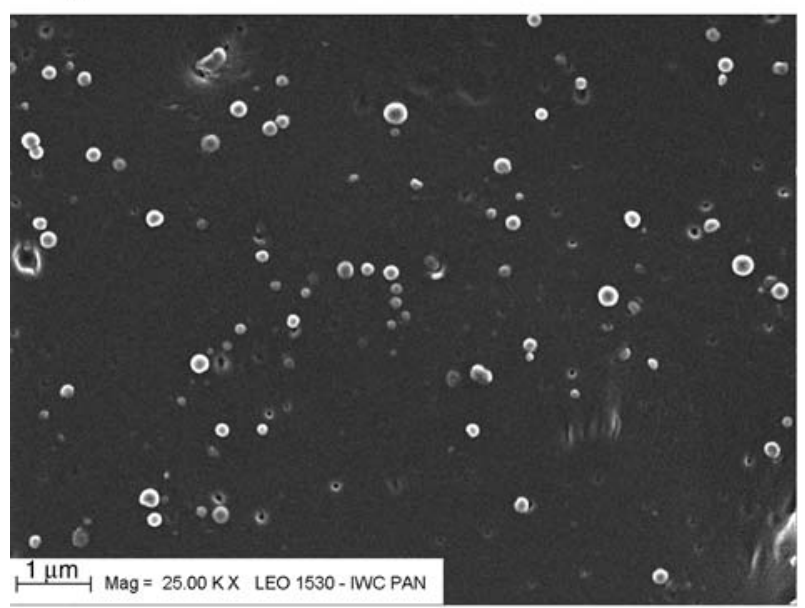

e)
$\mathrm{ZnO}$ nanoparticles are poorly dispersed in the elastomer matrix and therefore are not homogeneously distributed (Figure 10a). They create microsized clusters of particles (agglomerates) with complex structures. Additionally, the tendency of zinc oxide nanoparticles to agglomerate in the elastomer matrix was confirmed by rheological studies of zinc oxide suspensions in paraffin oil (model of

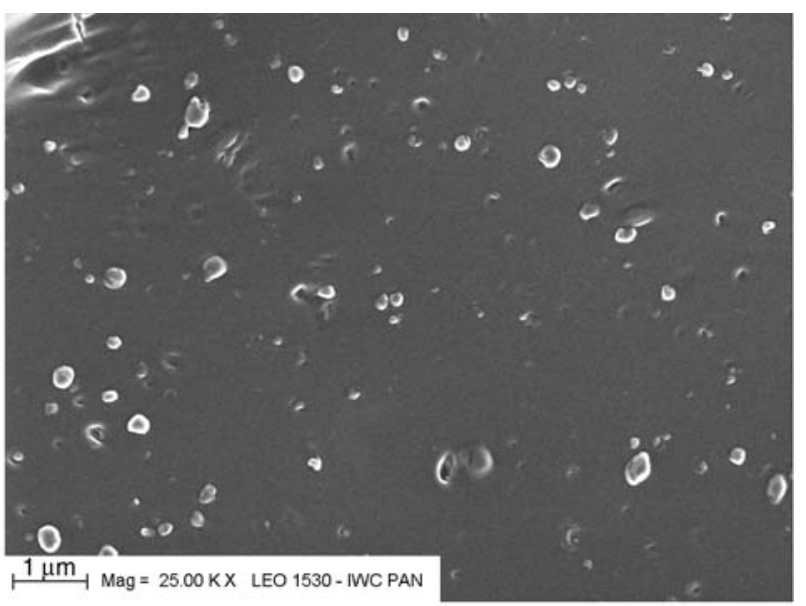

b)
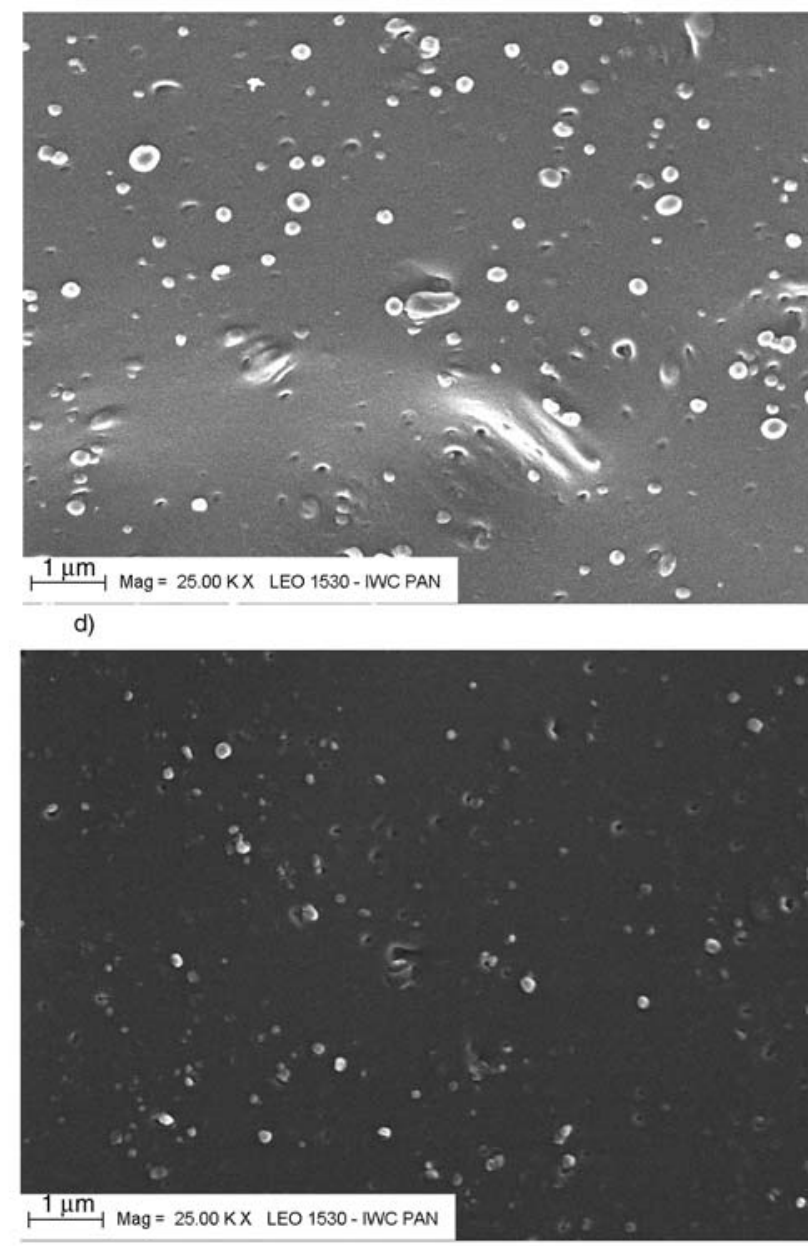

f)

Figure 10. SEM images of NBR vulcanizates a) with nanosized $\mathrm{ZnO}$, b) with BM-Zn, c) with MBM-Zn, d) with MBBM-Zn, e) with MMBM-Zn, f) with zinc acetylacetonate AAC-Zn 
elastomer matrix), presented in our previous work [22]. The agglomeration of zinc oxide particles causes their surface area to decrease followed by a decrease of the interface between the zinc oxide and other components of the crosslinking system. As a result, zinc oxide was observed to be less efficient as an activator of sulphur vulcanization. Moreover, agglomerates of zinc oxide particles may be responsible for local increases in crosslink density in vulcanizates, which may initiate breaking of the sample under external stress.

Zinc chelate particles, on the other hand, are homogenously distributed in the elastomer (Figures 10b-10f). The estimated size of zinc complex particles seems to be in the nanometer range, which makes their surfaces available for interactions. This is why their interactions with sulphur and accelerators are more efficient. Despite homogenous dispersion of particles, vulcanizates containing zinc complexes have more heterogeneous networks than vulcanizates crosslinked with zinc oxide as activator. The reason is that SEM micrographs show only the 'macro-dispersion', which is not identical with uniformity of the zinc ions concentration. The differences in dispersion of nanosized zinc oxide and zinc complexes are due to their different solubility and miscibility with elastomer as well as high surface energy of zinc oxide nanoparticles that results in their agglomeration [22].

\section{Conclusions}

Zinc acetylacetonate and zinc complexes with 1,3diketones were used as activators for sulphur vulcanization of NBR.

We conclude that zinc complexes are good substitutes for $\mathrm{ZnO}$ as activators in sulphur vulcanization of butadiene-acrylonitrile rubber, without any detrimental effect on the crosslinking rate, or physical properties of vulcanizates. The slight decrease in crosslinking density of vulcanizates and efficiency of crosslinking process did not influence their mechanical properties. Zinc 1,3-diphenylpropane-1,3-dione (BM-Zn) and zinc 1-(4'-t-butylphenyl)-3-phenylpropane-1,3-dione (BBM-Zn) were the most effective as crosslinking activators. The lower efficiency of zinc acetylacetonate and other examined zinc chelates is related to the stability of the complexes. In the more stable zinc complexes, the zinc ions are less available to form the active sulphurating agent (the zinc-accelerator complex that can react with allylic sites of elastomers unsaturations to form the crosslink precursor). Moreover, the steric hindrance of methoxy groups and t-butyl chains in a complex molecule of MBBM-Zn and MMBM-Zn seemed to reduce the availability of zinc ions during vulcanization.

As a general conclusion, we claim that zinc complexes with $\beta$-diketones applied in the crosslinking process help obtain vulcanizates with properties similar to those with nanosized $\mathrm{ZnO}$. This reduces the amount of zinc ions applied by $40 \%$ compared to zinc oxide. This is particularly relevant as reducing the use of $\mathrm{Zn}^{2+}$ ions is an important ecological goal.

\section{Acknowledgements}

The authors wish to acknowledge the Polish Ministry of Science and Higher Education for supporting this research.

\section{References}

[1] Chapman A., Johnson T.: The role of zinc in the vulcanisation of styrene-butadiene rubbers. Kautschuk Gummi Kunststoffe, 58, 358-361 (2005).

[2] Brydson J. A.: The Chemistry of Rubber. Applied Science, London (1978).

[3] Li Z. H., Zhang J., Chen S. J.: Effects of carbon blacks with various structures on vulcanization and reinforcement of filled ethylene-propylene-diene rubber. Express Polymer Letters, 2, 695-704 (2008). DOI: $10.3144 /$ expresspolymlett.2008.83

[4] Luyt A. S., McGill W. J., Shillington D.: A DSC study of the interaction of 2-mecraptobenzothiazole, sulphur, $\mathrm{ZnO}$ and stearic acid in the absence of rubber. British Polymer Journal, 23, 135-139 (1990). DOI: $10.1002 /$ pi.4980230122

[5] Kruger F. W. H., McGill J.: A DSC study of curative interactions. I. The interaction of $\mathrm{ZnO}$, sulfur, and stearic acid. Journal of Applied Polymer Science, 42, 2643-2649 (1991).

DOI: 10.1002/app.1991.070421002

[6] Coran A. Y.: Chemistry of the vulcanization and protection of elastomers: A review of the achievements. Journal of Applied Polymer Science, 87, 24-30 (2003).

DOI: 10.1002/app.11659

[7] Heideman G., Noordermeer J. W. M., Datta R. N., van Baarle B.: Effect of zinc complexes as activator for sulfur vulcanization in various rubbers. Rubber Chemistry and Technology, 78, 245-257 (2005). 
[8] Nieuwenhuizen P. J.: Zinc accelerator complexes: Versatile homogeneous catalysts in sulfur vulcanization. Applied Catalysis A: General, 207, 55-68 (2001). DOI: $10.1016 / \mathrm{S} 0926-860 \mathrm{X}(00) 00613-\mathrm{X}$

[9] Mark J. E., Eirich F. R., Erman B.: Science and technology of rubber. Academic Press, San Diego (1994).

[10] Chapman A. V., Porter M.: Sulphur vulcanization chemistry. in 'Natural rubber science and technology' (ed.: Roberts A. D.) Oxford University Press, Oxford, 511-620 (1988).

[11] Fritzsche J., Das A., Jurk R., Stöckelhuber K. W., Heinrich G., Klüppel M.: Relaxation dynamics of carboxylated nitrile rubber filled with organomodified nanoclay. Express Polymer Letters, 2, 373-381 (2008).

DOI: $10.3144 /$ expresspolymlett.2008.44

[12] Sae-oui P., Sirisinha C., Hatthapanit K.: Effect of blend ratio on aging, oil and ozone resistance of silicafilled chloroprene rubber/natural rubber (CR/NR) blends. Express Polymer Letters, 1, 8-14 (2007). DOI: 10.3144/expresspolymlett.2007.3

[13] Ohm R. F.: Rubber chemicals. in 'Kirk-othmer encyclopedia of chemical technology' (ed.: Howe-Grant M.) John Wiley and Sons, New York, Vol 21, 460481 (1997).

DOI: $\underline{10.1002 / 0471238961.18210202150813 . a 01}$

[14] Flory P. J., Rehner J.: Statistical mechanics of crosslinked polymer networks. II. Swelling. Journal of Chemical Physics, 11, 521-526 (1943).

DOI: $\underline{10.1063 / 1.1723792}$

[15] Baba M., Gardette J-L., Lacoste J.: Crosslinking on ageing of elastomers II. Comparison of solvent freezing point depression and conventional crosslinking evaluation. Polymer Degradation and Stability, 65, 415-420 (1999).

DOI: 10.1016/S0141-3910(99)00030-0
[16] Sun C., Berg J. C.: A review of the different techniques for solid surface acid-base characterization. Advances in Colloid and Interface Science, 105, 151175 (2003).

DOI: $10.1016 / \mathrm{S} 0001-8686(03) 00066-6$

[17] Zecchina A., Lamberti C., Bordiga S.: Surface acidity and basicity: General concepts. Catalysis Today, 41, 169-177 (1998).

DOI: $10.1016 / \mathrm{S} 0920-5861(98) 00047-9$

[18] Yin J., Liu Z. G., Liu H., Wang X. S., Zhu T., Liu J. M.: The epitaxial growth of wurtzite $\mathrm{ZnO}$ films on $\mathrm{LiNbO}_{3}$ (0001) substrates. Journal of Crystal Growth, 220, 281-285 (2000).

DOI: $10.1016 / \mathrm{S} 0022-0248(00) 00861-7$

[19] Shah G. B.: The effect of bimodality on tensile properties of filled silicone networks. Express Polymer Letters, 2, 878-884 (2008).

DOI: 10.3144/expresspolymlett.2008.102

[20] Hernandez L. G., Diaz A. R., de Benito Gonzales J. L., Orosa I. F., Fernandez A. M.: Effects of the structure and crosslink distribution on the physical properties of a natural rubber network: Comparison of sulfur, peroxide and benzene-1,3-disulfonylazide crosslinking systems. Kautschuk Gummi Kunststoffe, 45, 10331037 (1992).

[21] Vilgis T. A., Heinrich G.: New aspects in rubber elasticity: A challenge for theoretical physics and applied materials sciences. Kautschuk Gummi Kunststoffe, 45, 1006-1014 (1992).

[22] Zaborski M., Przybyszewska M.: Nanoparticle zinc oxide applied for crosslinking of butadiene rubbers. in '8th European Symposium on Polymer Blends and Eurofillers, Bruges, Belgium', 116 (2005). 